\title{
Microstructure and Properties of Semisolid A356 Alloy Strip Affected by Nozzle 'Temperature of a Novel Micro Fused-Casting
}

\author{
LUO Xiaoqiang ${ }^{1,2}$, LI Qingbin', XUE Lingwei', LI Yanling', HAN Yongjun', ZHOU Yanbiao' ${ }^{1 *}$ \\ (1. Henan Key Laboratory of Research for Central Plains Ancient Ceramics, Pingdingshan University, Pingdingshan 467000, China;2..Insti- \\ tute of Mechanics, Chinese Academy of Sciences, Beijing 100190, China)
}

\begin{abstract}
The semisolid A356 alloy strip was prepared by a novel continuous micro fused-casting process. The microstructure evolution and mechanical property of A356 aluminum alloy strip with different nozzle temperatures were investigated. The nozzle temperature had great influences on the microstructure and property primarily accompanied with the crystal change in the fused-casting area through the cooling conditions. The results showed that the semisolid A356 alloy strip samples fabricated by micro fused-casting demonstrated good performances and uniform structures with the nozzle temperature at $593{ }^{\circ} \mathrm{C}$ and the stirring velocity at $700 \mathrm{r} / \mathrm{min}$. The fine grains of the primary $\alpha$-Al phase with average grain size of $51 \mu \mathrm{m}$ and shape factor up to 0.71 were obtained under the micro fused-casting process, and the ultimate average vickers hardness came up to $83.39 \pm 0.89 \mathrm{HV}$, and the tensile strength and elongation of the A356 alloy strip reached $245.32 \mathrm{MPa}$ and $7.85 \%$, respectively.
\end{abstract}

Key words: semisolid; A356 aluminum alloy; nozzle temperature; micro fused-casting

\section{Introduction}

As a kind of super light metal structural materials, aluminum alloys have attracted significant interest in many applications including automobile and aerospace components for reducing the vehicles mass. The combination of high specific strength, good machinability, and high thermal conductivity are of prime concern ${ }^{[1-3]}$. These properties make aluminum and its alloys valuable in a system of applications including aerospace components and automobile for reducing the vehicles mass, and thus for minimizing fuel consumption and air pollution ${ }^{[4-6]}$. Micro fused-casting (MFC) without mold molding technology is a new kind of additive technology, which usually needs a semisolid metal liquid as raw material $^{[7,8]}$.

Semisolid forming of metals offers lots advan-

(C) Wuhan University of Technology and Springer-Verlag GmbH Germany, Part of Springer Nature 2020

(Received: Jan. 29, 2020; Accepted: May 18, 2020)

LUO Xiaoqiang(罗晓强): Ph D; Assoc. Prof.; E-mail: 1xq.5566 @163.com

*Corresponding author: ZHOU Yanbiao(周延彪): Ph D; Assoc. Prof.; E-mail: 349633279@qq.com

Funded by the National Natural Science Foundation of China(No. 51341009) tages over the traditional liquid forming of metals, such as lower processing temperature, reduction of solidification shrinkage, prolonged die and improved mechanical properties ${ }^{[9-11]}$. In general, the semisolid processing is mainly composed of three main processes, $i$ e, semisolid metal material production, remelting and forming. The key in semisolid forming technology is to produce semisolid metal slurry with non-dendritic microstructure. For the moment, the methods of obtaining semisolid metal material include electromagnetic stirring ${ }^{[12]}$, mechanical stirring ${ }^{[13]}$, liquidus cast and semisolid isothermal heat treatment ${ }^{[14]}$. Semisolid technology has abundance of special advantages and it has become a stimulate field of material forming technology researches ${ }^{[15-17]}$. In order to make full use of the advantages of semisolid forming technology, hunting for new and low-cost preparation methods has been an object for many experts. Recently, some new forming technologies of semisolid have appeared, such as micro fused-casting ${ }^{[18,19]}$.

In this work, an innovative processing of semisolid alloy strip, namely the MFC semisolid alloy strip process was introduced. The integral microstructure of semisolid A356 aluminum alloy strip by micro fused-casting process was studied, and the influences of nozzle temperature on the microstructure and prop- 
erties of semisolid A356 aluminum alloy strip were investigated.

\section{Experimental}

\subsection{Experimental procedures}

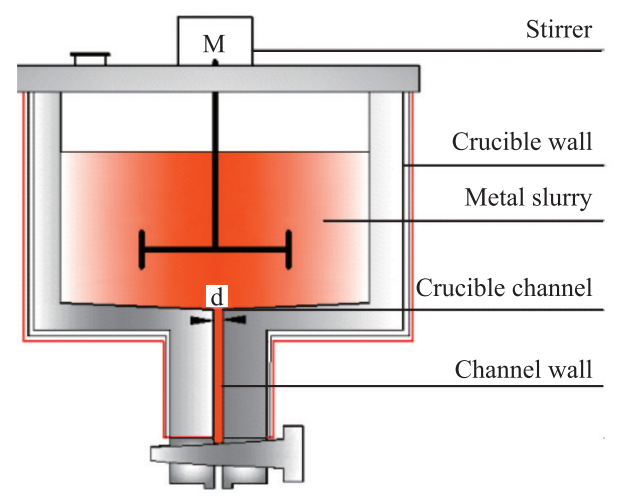

Fig.1 Micro fused-casting for semisolid alloy

The process principle of MFC continuous semisolid alloy experimental equipment is shown in Fig.1. It consists of high-strength graphite crucible with channel, a heating furnace and a mechanical stirrer. The experimental material was a commodity A356 aluminum alloy whose main chemical compositions (wt\%) were Si 7.36, Fe 0.28, Mg 0.289, Zn 0.21 and Al balanced. The solidus and liquidus temperatures of this alloy were 559.25 and $626.32{ }^{\circ} \mathrm{C}$, respectively. During the experimental process, the uniform semisolid slurry had been prepared in graphite crucible due to the strong shearing and cooling provided by the stirring, and the melt nucleated transformed into spherical primary grains gradually. In the channel, $\alpha$-Al grains gradually become round under the scouring of graphite channel wall. The semisolid slurry with fine non-dendrites was obtained. In the process, the nozzle temperature has a great influence on the morphology of the primary $\alpha-\mathrm{Al}$ phase and mechanical properties of semisolid A356 aluminum alloy strip through undercooling.

\subsection{Sample preparation}

The semisolid A356 aluminum alloy slurry was heated to a temperature between liquids and solidus zone which was required for semisolid slurry process. In this paper, we chose stirring velocity of $700 \mathrm{r} / \mathrm{min}$, the channel diameter of $3 \mathrm{~mm}$, substrate movement speed at $10 \mathrm{~cm} / \mathrm{s}$ and different nozzle temperatures. The samples for microstructure observation were prepared by standard metallographic techniques.

\subsection{Testing methods}

The average roundness and average grain size of the grains were calculated by image analysis software. The grain size was calculated as: $D=2(A / \pi)^{1 / 2}$ (where $A$ is the area of a grain), and the average roundness as: $S=L^{2} / 4 \pi A$ (where $L$ and $A$ are the area and perimeter of a grain, respectively). For microstructures observation, samples were cut off from the quenched slurries, roughly ground and polished and etched by an aqueous solution of $0.5 \% \mathrm{HF}$ for $10 \mathrm{~s}$. The etched samples were cleaned with an alcohol and dried, then analyzed by optical microscopy $(\mathrm{OM})$, and the representative microstructure of the slurry can be obtained. All the metallographic samples were examined by OM, SEM and EDS. T1 thermal treatment of the samples involved artificial aging. The semisolid A356 strip tensile sam-

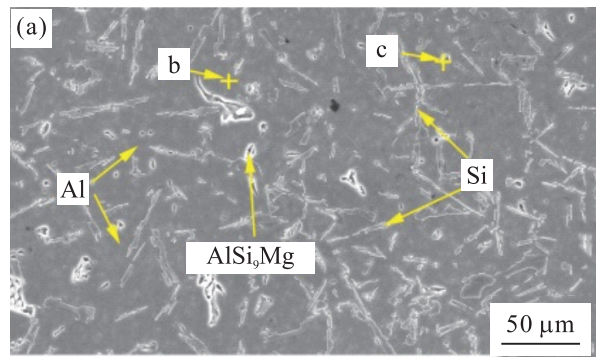

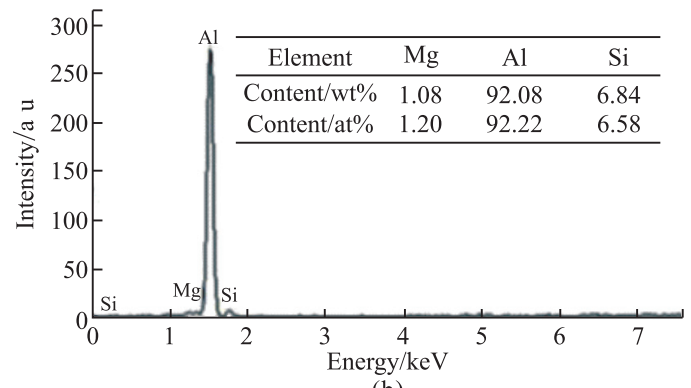

(b)

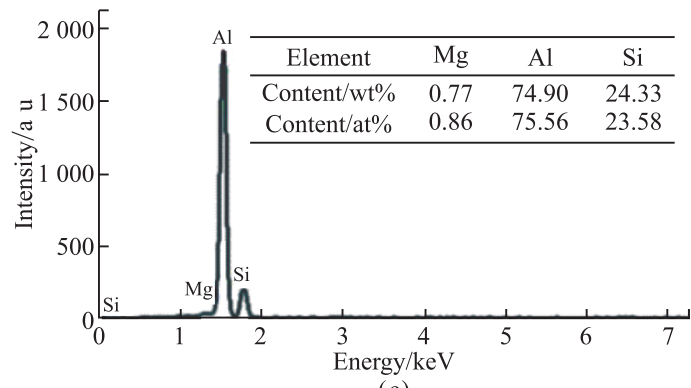

(c)

Fig.2 BSE image of A356 alloy material: (a) BSE of material; (b) the energy spectrum test results of position b; (c) the energy spectrum test results of position $\mathrm{c}$ 
ples for mechanical property tests were obtained from the middle region, and the tensile test was carried out by a CMT5105 tensile machine. The results of the tensile tests were the average obtained from five tensile test specimens. The hardness was test by an XHB-3000 Brilled durometer. The samples were conducted by using a $62.5 \mathrm{~kg}$ load and $5 \mathrm{~mm}$ diameter indentor, and the loading time was about $30 \mathrm{~s}$.

\section{Results and discussion}

\subsection{The microstructure of commodity $\mathbf{A 3 5 6}$ aluminum alloy}

Fig. 2 shows backscattered electron (BSE) image and EDS spectra of the sample with two regions of commodity A356 aluminum material which exhibits typical dendritic microstructure. Furthermore, it is found from BSE image that white needle-shaped precipitates is $\mathrm{Si}$ (point c), the shine precipitates is $\mathrm{AlSi}_{9} \mathrm{Mg}$, the grey precipitates is $\alpha$-Al (point b), and the microstructure of commodity A356 alloy is mainly composed of matrix $\alpha$-Al and eutectic Si phase. According to the EDS results of A356 aluminum material alloy, it is confirmed that arrow "c" (white needle-shaped precipitates) and the arrow "b" (grey precipitates) in Fig. 2 are eutectic $\mathrm{Si}$ and eutectic $\alpha$-Al phases, respectively. As can be seen from Fig.2, the A356 aluminum alloy has microstructure in complex irregular shape, the Si phase is needle-shaped, and the $\alpha$-Al is grey precipitates alloy mainly exhibiting a large block shape.

\subsection{Effect of the nozzle temperature on the microstructure of semisolid $\mathbf{A 3 5 6}$ alumi- num alloy}

The dendrite became short grain with the undercooling and action of shear force in the areas of graphite crucible. Fig. 3 shows the optical microstructure of four semi-solid samples. The four samples were made by MFC with stirring velocity at $700 \mathrm{r} / \mathrm{min}$ and different nozzle temperatures. The four samples are high temperature molded without cold working besides cooling (T1 state). The nozzle temperature has a significant influence on the material morphology. The process of MFC is focused on solidification and melting. The low nozzle temperature combined with rapid stirring made the dendrite become short grain, so as to achieve the goal of fine grains. A lot of big and irregular grains were observed in Fig.3(d). The sample prepared under nozzle temperature at $593{ }^{\circ} \mathrm{C}$ and stirring velocity at $700 \mathrm{r} / \mathrm{min}$ has the most uniform microstructure and small shape.

Fig. 4 shows the relationships between the nozzle temperatures, average grain size and average roundness. The primary grain size is best developed at nozzle temperature of $593{ }^{\circ} \mathrm{C}$, the nozzle temperature can affect the nucleation rate of the slurry, and further influence the final grain size of the A356 alloy slurry. The average roundness and average grain size increased with increasing nozzle temperature from $593{ }^{\circ} \mathrm{C}$. On one hand, when the nozzle temperature is high, the inner wall of the nozzle channel will be heated, resulting in that the chilling effect is weakened and the nucleation ratio will decrease; on the other hand, the primary $\alpha(\mathrm{Al})$ grains will be remelted under the circumstances of the strong degree of superheat near the nozzle mouth. If the nozzle temperature is lower, the temperature of the alloy melt in the channel will rapidly drop below the liquidus temperature and the temperature of the inner wall is lower. So the alloy melt has more time and bigger super-cooling to nucleate. However, when the nozzle temperature is too low, the thickness of solidified shell in the nozzle channel increases quickly,

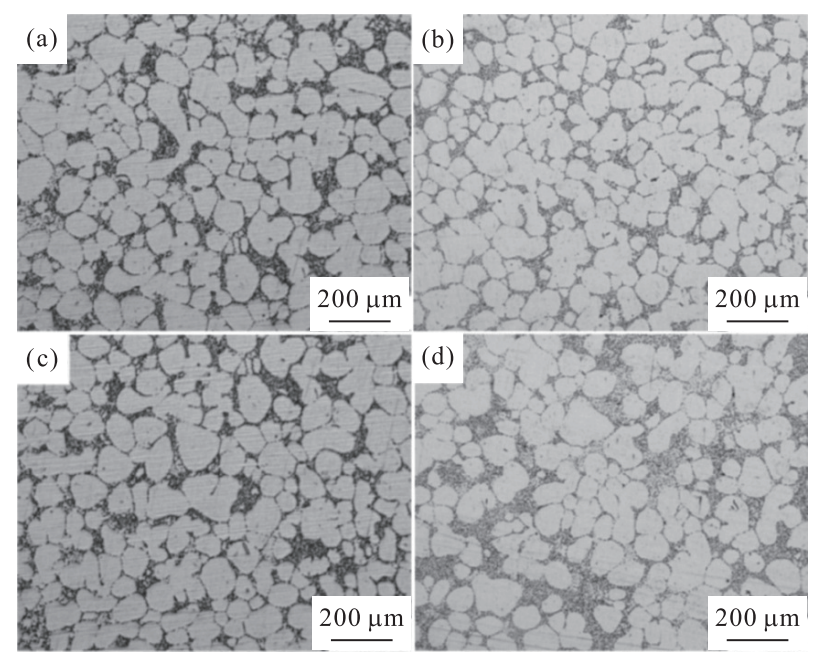

Fig.3 OM images of the semisolid experimental alloy at different nozzle temperatures: (a) $590{ }^{\circ} \mathrm{C}$, (b) $593{ }^{\circ} \mathrm{C}$, (c) $596{ }^{\circ} \mathrm{C}$, (d) $599{ }^{\circ} \mathrm{C}$

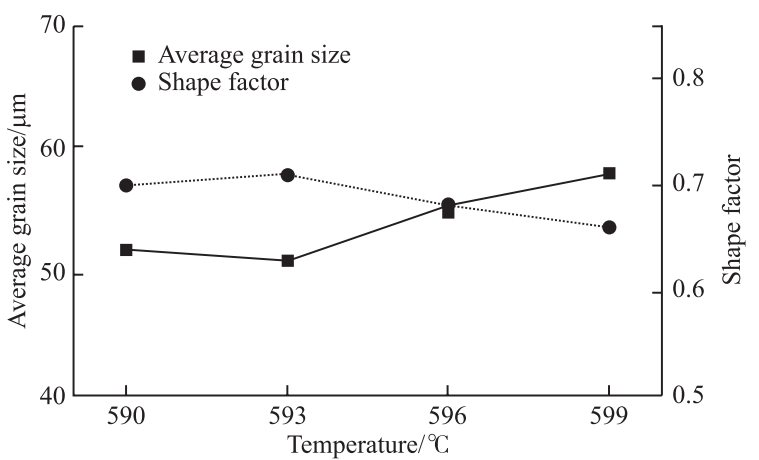

Fig.4 Curves of nozzle temperatures vs average grain size and shape factor of A356 alloy slurry 
and the chilling effect of the nozzle channel will be weakened. The solidified shells form in the nozzle and the nozzle exit easily to jam. For these reasons, we suggest a reasonable nozzle temperature of $593{ }^{\circ} \mathrm{C}$. At this point, the average grain size and shape factor reach 51 $\mu \mathrm{m}$ and 0.71 , respectively.

\subsection{Effect of the nozzle temperature on the} microstructure and properties of semisolid A356 aluminum alloy strip
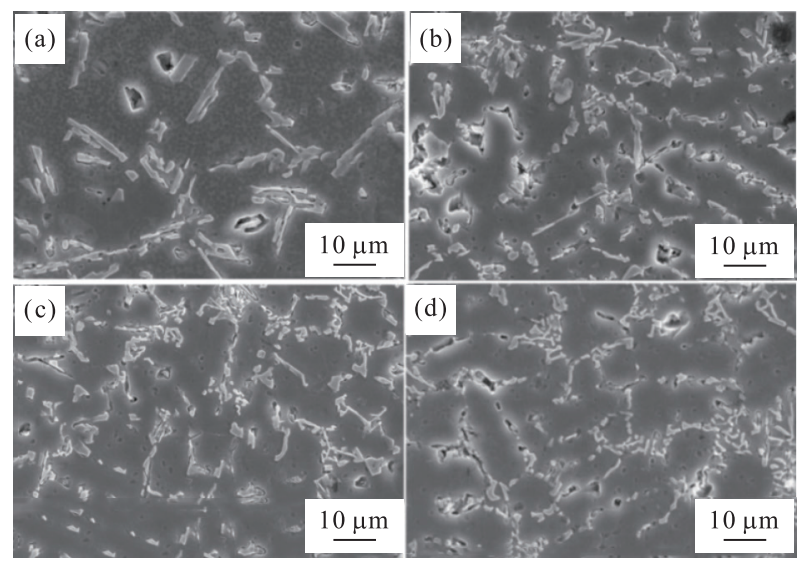

Fig.5 SEM images of the semisolid experimental alloy at different nozzle temperatures: (a) $590{ }^{\circ} \mathrm{C}$, (b) $593{ }^{\circ} \mathrm{C}$, (c) $596{ }^{\circ} \mathrm{C}$, (d) $599{ }^{\circ} \mathrm{C}$

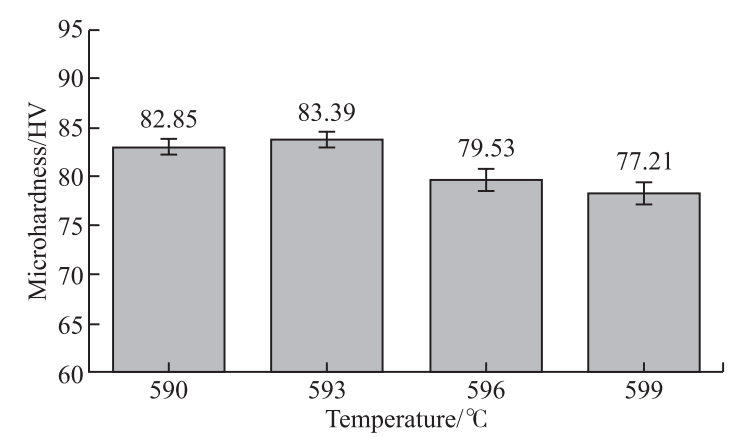

Fig.6 Vickers hardness of semisolid A356 alloy strip at different nozzle temperatures

Fig.5 shows the scanning electron microscopy of four aluminum alloy strip samples. The samples were made by MFC with substrate movement speed at $10 \mathrm{~cm} / \mathrm{s}$, stirring velocity at $700 \mathrm{r} / \mathrm{min}$ and different nozzle temperatures. Four samples are molded at high temperature without cold working besides cooling (T1 state). The nozzle temperature could change the cooling rate of melt. During the cooling process, rapid cooling is beneficial for grain refinement. However too high nozzle temperature could make the grain organization segregate and reduce the mechanics performance of material. According to the results, the nozzle temperature of experimental alloy strips treated at $593{ }^{\circ} \mathrm{C}$ has a uniform microstructure and there is very few dendritic. Obviously, the nozzle temperature at $593{ }^{\circ} \mathrm{C}$ could maintain the balance of melting and solidification of the material.

Fig. 6 shows the relationship between the nozzle temperature and Vickers hardness. The Vickers hardness is best developed at $593{ }^{\circ} \mathrm{C}$. This nozzle temperature can influence the undercooling and grain size of the melt in the fused-casting zones, and further affect the Vickers hardness of the semisolid A356 alloy. The nucleation rate decreased with the nozzle temperature increasing from $593{ }^{\circ} \mathrm{C}$. Furthermore, the liquid fraction of the A356 slurry increased with the increasing increments of the nozzle temperature, and shape factor decreased correspondingly. As stated, the undercooling in the melt is determined by the nozzle temperature, so the nozzle temperature reduces with the decrease of the crystal size of A356 slurry. For this reason, a low nozzle temperature could have caused a high nucleation rate, which caused globular crystals formation and better mechanical property of semisolid A356 aluminum alloy strip.

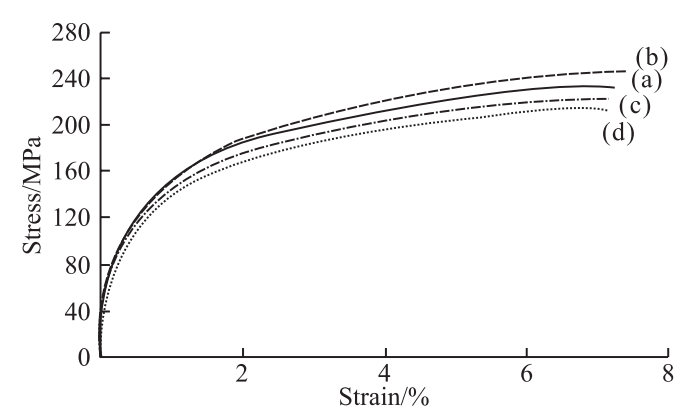

Fig.7 Tensile strength and elongation chart of aluminum alloy strip treated at different nozzle temperatures: (a) $590{ }^{\circ} \mathrm{C}$, (b) $593{ }^{\circ} \mathrm{C}$, (c) $596{ }^{\circ} \mathrm{C}$, (d) $599{ }^{\circ} \mathrm{C}$

Fig.7 shows the relationships between the nozzle temperature, tensile strength and elongation of the aluminum alloy strip. As mentioned above, the undercooling in the melt is determined by the nozzle temperature, so the nozzle temperature reduces with the decrease of the crystal size of A356 slurry. For this reason, a high nozzle temperature could have caused a low nucleation rate, which caused globular crystals formation. Therefore, the most tensile strength is the metal components produced with the nozzle temperature at $593{ }^{\circ} \mathrm{C}$. The ultimate tensile strength and elongation of the A356 alloy strip reached $245.32 \mathrm{MPa}$ and $7.85 \%$, respectively. Obviously, the nozzle temperature at $593{ }^{\circ} \mathrm{C}$ could maintain the balance of melting and solidification of the material. 


\section{Conclusions}

a) The experimental samples were prepared by a novel semisolid MFC proces. The proper nozzle temperature could contribute to grain refinement and evenly affected the microstructure and mechanics of strip samples.

b) The proper nozzle temperature has great influences on the microstructure and properties of strip samples. When the nozzle temperature of MFC for semisolid A356 aluminum alloy strip is controlled at $593{ }^{\circ} \mathrm{C}$, the best microstructure and mechanical performance were obtained, the tensile strength and elongation of the semisolid A356 alloy strip reached 245.32 MPa and $7.85 \%$, respectively.

\section{References}

[1] Sercombe T B, Schaffer G B. Rapid Manufacturing of Aluminum Components[J]. Science, 2003, 301(5 637): $1225-1227$

[2] Zhao Z, Mao W, Li S, et al. Preparation of Semisolid AlSi7Mg Alloy Slurry Through Weak Traveling-wave Electromagnetic Stirring[J] International Journal of Minerals, Metallurgy and Materials, 2009, 16(5): 554-558

[3] Guan R, Zhao Z, Lian C, et al. Mathematic Model of Rolling Pressure During a Semisolid Shearing-rolling Process[J]. International Journal of Minerals, Metallurgy and Materials, 2012, 19(12): 1 121-1 127

[4] Liu Z, Mao W, Zhao Z. Effect of Pouring Temperature on Semi-solid Slurry of A356 Al Alloy Prepared by Weak Electromagnetic Stirring[J] Transactions of Nonferrous Metals Society of China, 2006, 16(1): 7176

[5] Mazzolani F M. 3D Aluminium Structures[J]. Thin-Walled Structures, 2012, 61: 258-266

[6] Liu Z, Mao W, Zhao Z. Research on Semi-solid Slurry of A HypoeuTectic Al-Si Alloy Prepared by Low Superheat Pouring and Weak Electromagnetic Stirring[J]. Rare Metals, 2006, 25(2): 177-183

[7] Luo X, Han Y, Li Q, et al. Microstructure and Properties of ZL101 Alloy Affected by Substrate Movement Speed of a Novel Semisolid Continuous Micro Fused-Casting for Metal Process[J]. Journal of Wuhan University of Technology, 2018(03): 715-719

[8] Luo X, Han Y, Li Q, et al. Effect of Pouring Temperature on Microstructure and Properties of A356 Alloy Strip by a Novel Semisolid
Micro Fused-Casting for Metal[J]. Journal of Wuhan University of Technology, 2019(05): 1 205-1 209

[9] Liu Z, Mao W, Zhao Z. Effect of Pouring Temperature on Semi-solid Slurry of A356 Al Alloy Prepared by Weak Electromagnetic Stirring[J]. Transactions of Nonferrous Metals Society of China, 2006, 16(1): 7176

[10] Guan R G, Zhao Z, Lian C, et al. Microstructure Formation Mechanism and Properties of a Mg-3Sn-1Mn (wt\%) Magnesium Alloy Processed by A Novel Semisolid Continuous Shearing and Rolling Process[J]. Metals and Materials International, 2013, 19(1): 33-38

[11] Qi M, Kang Y, Zhou B, et al. A Forced Convection Stirring Process for Rheo-HPDC Aluminum and Magnesium Alloys[J]. Journal of Materials Processing Technology, 2016, 234: 353-367

[12] Wang S, Cao F, Guan R, et al. Formation and Evolution of Non-dendritic Microstructures of Semi-solid Alloys Prepared by Shearing/ Cooling Roll Process[J]. Journal of Materials Science and Technology, 2006, 22(2): 195-199

[13] Flemings M. Behavior of Metal Alloys in the Semisolid State[J]. Metallurgical Transactions B, 1991, 22(3): 269-293

[14] Wang X, Yan Y, Pan Y, et al. Generation of Three-dimensional Hepatocyte/Gelatin Structures with Rapid Prototyping System[J]. Tissue Engineering, 2006, 12(1): 83-90

[15] Guan R, Zhao Z, Zhang H, et al. Microstructure and Properties of Mg$3 \mathrm{Sn}-1 \mathrm{Mn}(\mathrm{wt} \%)$ Alloy Processed by A Novel Continuous Shearing and Rolling and Heat Treatment[J]. Materials Science and Engineering: A, 2013, 559: 194-200

[16] Nafisi S, Ghomashchi R. Grain Refining of Conventional and Semi-solid A356 Al-Si Alloy[J]. Journal of Materials Processing Technology, 2006, 174(1-3): 371-383

[17] Khosravi H, Eslami-farsani R, Askari-paykani M. Modeling and Optimization of Cooling Slope Process Parameters for Semi-solid Casting of A356 Al Alloy[J]. Transactions of Nonferrous Metals Society of China, 2014, 24(4): 961-968

[18] Luo X, Li Z, Si X, et al. Effect of Stirring Velocity in Micro Fused-Casting for Metal on Microstructure and Mechanical Properties of A356 Aluminum Alloy Slurry[J]. Journal of Wuhan University of Technology, 2016(05): 1 131-1 136

[19] Luo X, Yan Q, Li Z. Effect of the Pouring Temperature by Novel Synchronous Rolling-casting for Metal on Microstructure and Properties of ZL104 Alloy[J]. Journal of Materials Research, 2016, 31(16): 2 524-2 530 